\title{
Surge-Resistant Nanocomposite Enameled Wire Using Silica Nanoparticles with Binary Chemical Compositions on the Surface
}

\author{
Jeseung Yoo,, ${ }^{1}$ Yongbeom Kim, ${ }^{1}$ Suyong Kwon, ${ }^{2}$ Joohyun Lee, ${ }^{2}$ and Young-Soo Seo ${ }^{1}$ \\ ${ }^{1}$ Department of Nano Science \& Technology, Sejong Polymer Research Center, Sejong University, Seoul 05006, Republic of Korea \\ ${ }^{2}$ Center for Thermometry, Division of Physical Metrology, Korea Research Institute of Standards and Science, \\ Daejeon 34113, Republic of Korea
}

Correspondence should be addressed to Young-Soo Seo; ysseo@sejong.ac.kr

Received 12 August 2015; Revised 26 October 2015; Accepted 27 October 2015

Academic Editor: John Zhanhu Guo

Copyright (C) 2015 Jeseung Yoo et al. This is an open access article distributed under the Creative Commons Attribution License, which permits unrestricted use, distribution, and reproduction in any medium, provided the original work is properly cited.

\begin{abstract}
We developed polyesterimide (PEI) nanocomposite enameled wires using surface-modified silica nanoparticles with binary chemical compositions on the surface. The modification was done using silanes assisted by ultrasound, which facilitated high density modification. Two different trimethoxysilanes were chosen for the modification on the basis of resemblance of chemical compositions on the silica surface to PEI varnish. The surface-modified silica was well dispersed in PEI varnish, which was confirmed by optical observation and viscosity measurement. The glass transition temperature of the silica-PEI nanocomposite increased with the silica content. The silica-dispersed PEI varnish was then used for enameled wire fabrication. The silica-PEI nanocomposite enameled wire exhibited a much longer lifetime compared to that of neat PEI enameled wire in partial discharge conditions.
\end{abstract}

\section{Introduction}

Enameled wire is composed of conductive copper or aluminum core surrounded by an insulation layer made of polymer. The lifespan of the electric motor is strongly dependent on thermal and electrical properties of the insulation layer. In a high speed switching inverter-fed motor, especially, when instantaneous overlapping voltage called surge voltage is higher than partial discharge inception voltage (PDIV), the insulation layer is degraded by partial discharge (PD), which leads to insulation breakdown [1-4]. For this reason, surgeresistant enameled wire has attracted attention for prolonging the lifespan of various inverter-fed motor installed electric devices such as electric vehicles. For protection from the degradation, nanosized inorganic fillers were incorporated in the insulation layer [5-8] where corona evolved by PD can be trapped on or reflected from the surface of the inorganic filler so that the degradation would be retarded [9-11].

Polyesterimide (PEI) was frequently chosen for the insulation layer of high temperature enameled wires because it meets both requirements [12-14] of high thermal index and flexibility sufficient to withstand severe stress while winding. There are many reports regarding the enhanced breakdown time of PEI enameled wire by adding inorganic nanoparticles such as silica, alumina, and clay in the insulation layer. In 2002, Hitachi Cable Ltd. developed silica nanoparticlePEI nanocomposite enameled wire having breakdown time of $42 \mathrm{~min}$ compared to $1 \mathrm{~min}$ for one without silica in the PD condition of $2.8 \mathrm{kV}$ and $10 \mathrm{kHz}$ [15]. Since then, surge-resistant properties of nanocomposite enameled wire have been systematically studied $[1,11,16-18]$. As expected, the breakdown time increased with nanoparticle volume fraction on the condition that the nanoparticles are uniformly dispersed.

Because it is difficult to disperse nanoparticle in a viscous varnish solution, the sol-gel method, which has a great advantage for dispersion, has attracted attention. In the sol-gel method, nanoparticles are easily dispersed in the insulation layer as soon as they are synthesized from the precursors premixed in the varnish during the wire annealing 

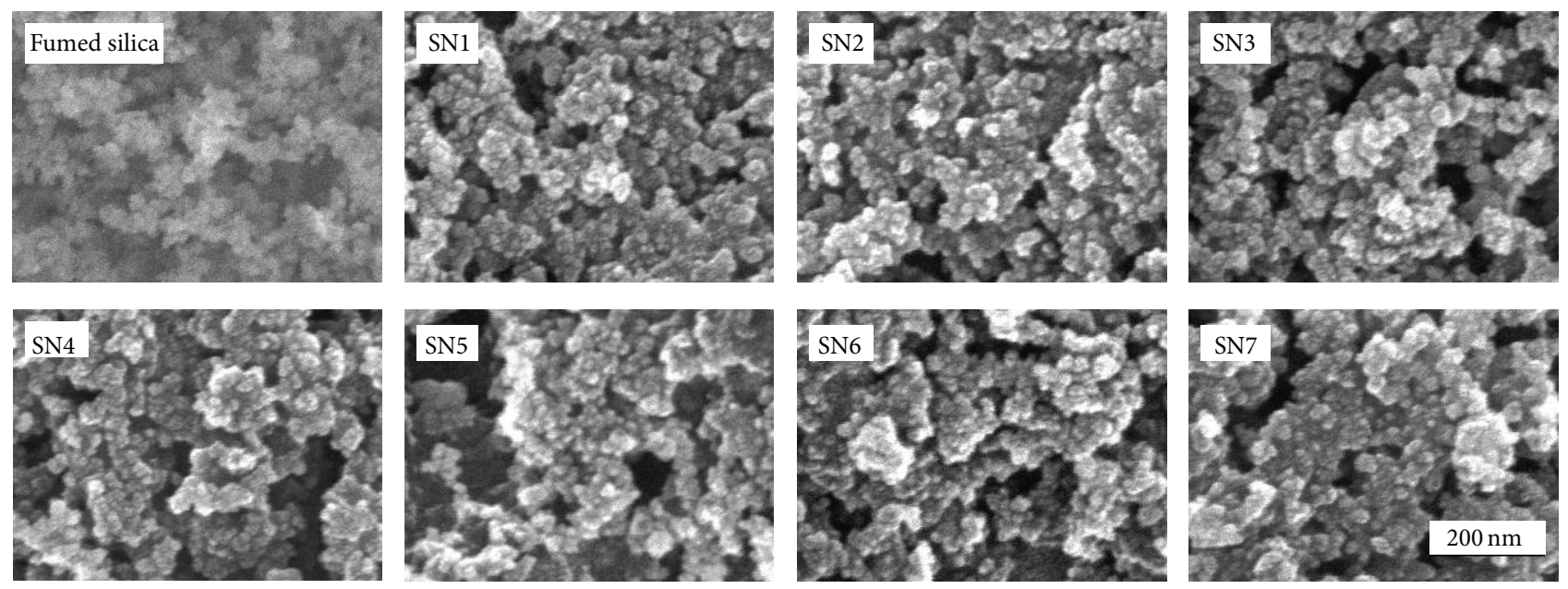

FIGURE 1: SEM images of fumed silica, modified nanoparticles of SN1 to SN7.

process accompanied by a coating process [12, 19]. However, serious problems were revealed; for example, the enameled wire production cost increased because the process was too slow and the breakdown strength of the enameled wire was reduced due to impurities remaining from the sol-gel process $[20,21]$. In order to avoid such problems, nanoparticles need to be directly dispersed in the varnish and therefore should be properly surface-modified $[6,13]$.

Here we propose a novel surface modification method in which silica nanoparticles are chemically modified using two kinds of silanes, selected based on the fact that their chemical composition on the silica surface matches that of the varnish, resulting in binary chemical compositions forming on the silica surface. Silanes are highly reactive to form chemical bond with silanol group on the silica. During the silanation, ultrasound was applied so that the reaction rate was accelerated and the surface coverage was increased. We found that the surface-modified silica nanoparticles were uniformly dispersed in PEI varnish. The silica nanoparticle dispersed PEI varnish was then applied for the nanocomposite enameled wires fabrication in commercial facilities. Surge resistance properties of the nanocomposite enameled wire were investigated.

\section{Experimental}

Fumed silica was purchased from Sigma-Aldrich, which has an average size of $11 \mathrm{~nm}$ with a specific area of $255 \pm$ $15 \mathrm{~m}^{2} / \mathrm{g}$. Fumed silica nanoparticles were used because they are known as their excellent property for preventing PDinduced breakdown [22]. Silanes also from Sigma-Aldrich were used without further purification. Cresol was a thinner for polyesterimide and polyamideimide varnish with a solid content of 39 wt\%, which were supplied by Komec Co., Korea.

For surface modification of silica with silanes, $12 \mathrm{~g}$ of fumed silica was added into $600 \mathrm{~mL}$ of toluene in a $1,000 \mathrm{~mL}$ glass bottle. The bottle was sonicated for 30 minutes at $85^{\circ} \mathrm{C}$ using a bath-type sonicator $(60 \mathrm{~W}, 28 \mathrm{kHz})$ in order to disperse fumed silica in toluene. The solution temperature was kept for $85^{\circ} \mathrm{C}$ during the following silanation reaction. Table 1 lists silane modified silica from SN1 to SN7. For single silane modification (SN1 and SN6), $10 \mathrm{~g}$ of silane was added to the solution and ultrasonication was applied for 3 days. For double silane modification (SN2, SN3, SN5, and SN7), $8 \mathrm{~g}$ of first silane was added to the solution and ultrasonication for $3 \mathrm{~h}$. Successively, $2 \mathrm{~g}$ of second silane was added and sonicated for 3 days. For triple silane modification (SN4), $8 \mathrm{~g}$ of first silane was added to the solution and sonicated for $3 \mathrm{~h} .2 \mathrm{~g}$ of second silane was added and sonicated for $3 \mathrm{~h}$, and then $1 \mathrm{~g}$ of third silane was added and sonicated for 3 days. After the reaction, the solution was mixed with ethanol and then filtered using a glass filter funnel. Gel-like filtrates were washed five times with ethanol to remove unreacted silanes and then dried in an oven at $110^{\circ} \mathrm{C}$ overnight.

Scanning electron microscope (SEM) image was taken using field emission-SEM (FE-SEM, Hitachi, S-4700). Viscosity of the varnish solution was measured using a Brookfield viscometer. Glass transition of the silica-PEI nanocomposites was measured using differential scanning calorimeter (DSC, Mettler-Toledo, DSC1). Surge endurance test was done using a PD tester (SungMin Instrument, Korea).

\section{Results and Discussion}

3.1. Surface Modifications. Figure 1 shows SEM images of silane modified silica particles. Silane directly reacts with hydroxyl group on the surface of silica, forming a permanent chemical bond. Particle size is indistinguishable from SN1 to SN7, which is still bigger by few nanometers than fumed silica particle, indicating that fumed silica is covered by an organic layer. As previously reported [22], the area occupied by ANMS $\left(92.1 \AA^{2}\right)$ is 3.6 times bigger than DAMS $\left(25.6 \AA^{2}\right)$ on the fumed silica surface due to greater steric hindrance of ANMS than DAMS. From SN1 to SN4, in which cases ANMS was treated first, the area occupied by a silane lies in between those two values, which indicates, paradoxically, that the first treatment by ANMS may allow further surface modification using smaller sized silane. This reaction requires high energy 
TABLE 1: Single, double, and triple silane modified silica nanoparticles.

(a)

\begin{tabular}{lccc}
\hline Name & First silane & Second silane & Third silane \\
\hline SN1 & ANMS & - & - \\
SN2 & ANMS & DAMS & - \\
SN3 & ANMS & TMMS & - \\
SN4 & ANMS & DAMS & TMMS \\
SN5 & DAMS & TMMS & - \\
SN6 & TAMS & & - \\
SN7 & TAMS & TMMS & - \\
\hline
\end{tabular}

(b)

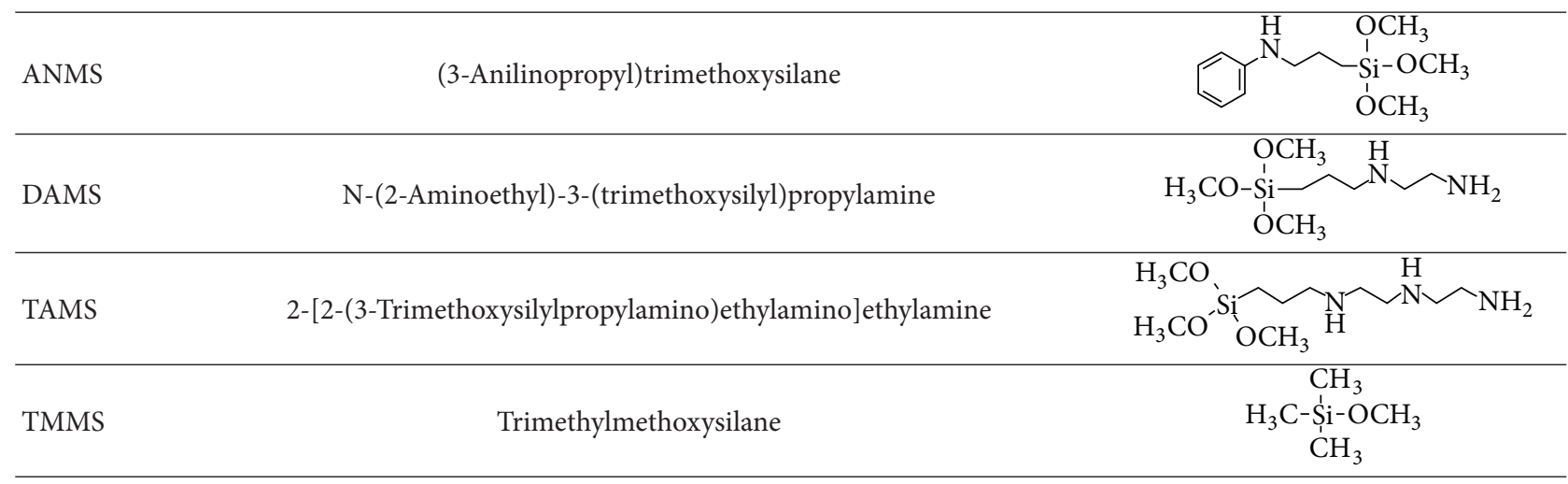

provided by cavitation effects generated by ultrasound. The first TAMS treatment cases (SN6 and SN7) are similar to the DAMS case (SN5). It is noted that polymerization reaction between the silanes was minimized during the surface modification.

3.2. Dispersion in Cresol. The dispersion state of the silane modified silica from SN1 to SN7 was checked. After they were dissolved in cresol with a solid content of $15 \mathrm{wt} \%$ assisted by ultrasonication at $85^{\circ} \mathrm{C}$, where cresol is a thinner for PEI varnish, they were left at room temperature for a day and checked visually clearness of the solution. Figure 2 shows the result of the dispersion. ANMS exhibits better compatibility than the other silanes. Unlike the previous result [22] where ANMS-TMMS dual silane modified silica (here, SN3) was well dissolved in cresol-xylene mixture solvent, ANMSDAMS silica (SN2) exhibits the best dispersion state in cresol alone. Even though ANMS modified silica (SN1) was also dispersed in cresol, it required a longer sonication time for dispersion and was much more viscous than SN2 in cresol. ANMS-DAMS-TMMS triple silane modified silica (S4) was not dispersed because small TMMS molecules consumed silanol groups on the silica faster than DAMS. SN5, SN6, and SN7, where DAMS or TAMS was used as a first silane for the modification, did not result in good compatibility to cresol, which indicates that these molecules are less compatible to cresol than ANMS.

3.3. Surface Modification Using Bath- and Horn-Type Sonicator. Unlike a bath-type sonicator, the ultrasound generating

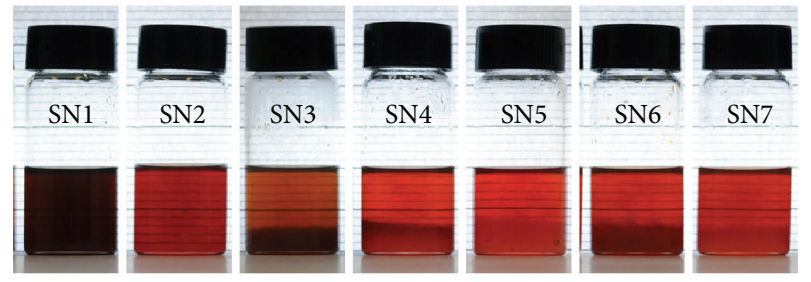

FIGURE 2: Dispersion test of silane modified silica from SN1 to SN7 in cresol.

horn in a horn-type sonicator directly contacts with reaction solution. Here we used a horn-type sonicator $(200 \mathrm{~W}, 20 \mathrm{kHz}$, Janosonic, Co., South Korea), which has higher power than the bath-type sonicator $(60 \mathrm{~W}, 28 \mathrm{kHz})$, for SN2 preparation. For the bath-type sonicator, after ANMS was added to the solution, 3-hour sonication was applied, while for a horntype sonicator $30 \mathrm{~min}$ sonication was applied, followed by DAMS addition, and further sonication was applied. SN2 obtained from both methods was dissolved using the horntype sonicator for 3 hours in cresol. The solubility of SN2 was checked in terms of total sonication time for the silane reaction as shown in Figure 3. The dispersion state of SN2 was easily checked by turning the bottle upside down. Using a bath-type sonicator, 72-hour sonication for silane modification was required for complete dispersion in cresol. On the other hand, 3.5-hour sonication was enough using a horntype sonicator. Therefore, the horn-type sonicator is much faster than the bath-type sonicator for the complete silane reaction, though considering its higher power compared to 


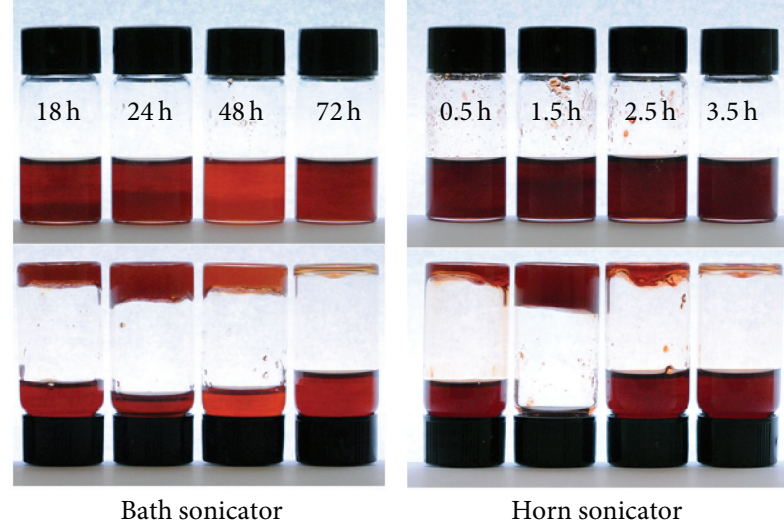

FIGURE 3: Sonication time for SN2 preparation using bath- and horn-type sonicator. $20 \mathrm{wt} \% \mathrm{SN} 2$ was dissolved in cresol for checking solubility.

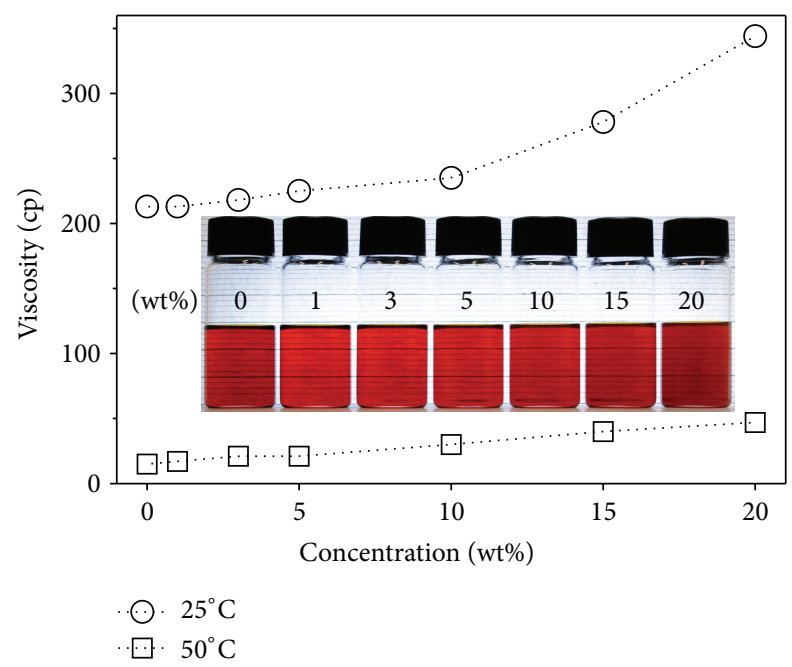

FIGURE 4: Viscosity of SN2-PEI varnish solution and solution bottles in inset.

the bath-type sonicator. This implies that high sonication power facilitates the effective reaction of DAMS with a silanol group by overcoming the steric hindrance of ANMS.

3.4. Dispersion in PEI Varnish. SN2-PEI varnish solution was prepared by simply mixing SN2 dissolved in cresol with PEI varnish. The SN2 content is $0,1,3,5,10,15$, and $20 \mathrm{wt} \%$ in PEI varnish. Alternatively, it can be prepared by directly dissolving dry SN2 in PEI varnish assisted by ultrasonication. The former method was faster than the later one, but the results are the same. Each solution was transparent to $20 \mathrm{wt} \%$ SN2 as shown in Figure 4 inset, indicating that SN2 is well dissolved in PEI varnish.

Solubility of SN2 was also checked by viscosity of the solution, which is important in the enameled wire coating process because it determines coating thickness and flatness. The viscosity of the solution was measured at 25 and $50^{\circ} \mathrm{C}$. At $25^{\circ} \mathrm{C}$, the viscosity of the PEI varnish was measured to 213 centipoises (cp). It steadily increases as the SN2 concentration increases up to $10 \mathrm{wt} \%$ and then steeply increases. At $50^{\circ} \mathrm{C}$, on the other hand, which is close to the usual PEI varnish bath temperature in enameled wire fabrication, the varnish viscosity steadily increases as the $\mathrm{SN} 2$ concentration increases up to $20 \mathrm{wt} \%$.

The organic content of SN2 was obtained after burning it at $600^{\circ} \mathrm{C}$ for $2 \mathrm{~h}$ accompanied by drying at $200^{\circ} \mathrm{C}$ for $2 \mathrm{~h}$, which was $13.0 \mathrm{wt} \%$. This value lies in between $6.0 \mathrm{wt} \%$ for SN3 and $16.3 \mathrm{wt} \%$ for SN5. It is certain that both ANMS and DAMS exist on the silica surface in the SN2 sample, even though exact proportion of each silane is unclear. Again, it is confirmed that dual silane modification, that is, ANMS treatment followed by DAMS treatment, has been accomplished assisted by ultrasonic power. Figure 5 shows schematic drawing for chemical structure of SN2, cresol, and PEI varnish. SN2 is composed of both the nonpolar benzene ring and the polar amine group on its surface, that is, binary chemical compositions. Cresol and PEI varnish also have both polar and nonpolar characters. Therefore, the surface chemical structure of SN2 is quite similar to cresol as well as PEI varnish as shown in the figure. In this way, we believe that surface character of nanoparticles can be tailored by using two or more kinds of silanes, enhancing compatibility to the matrix environment for the dispersion.

3.5. Analysis of SN2/Polyesterimide Nanocomposites. SN2/polyesterimide nanocomposite sample was prepared by thermal curing in the following procedure. SN2 dispersed PEI varnish was transferred into a $40 \mu \mathrm{L}$ aluminum pan used for differential scanning calorimeter (DSC) measurement. Then, the pan was placed in an oven successively at $120^{\circ} \mathrm{C}$ for $30 \mathrm{~min}$, at $170^{\circ} \mathrm{C}$ for $45 \mathrm{~min}$, and at $230^{\circ} \mathrm{C}$ for $2 \mathrm{~h}$.

The surface of thermally cured neat PEI as well as SN2PEI composites was flat according to the FE-SEM images as shown in Figure 6. There is no indication of large sized aggregate on the surface. Dispersion of SN2 in the nanocomposite can be checked by dipping it into $49 \%$ hydrofluoric acid solution to dissolve silica particles existing in the close vicinity of the surface. After the treatment, the neat PEI sample exhibited a flat surface without any holes. On the other hand, on the $10 \mathrm{wt} \% \mathrm{SN} 2-\mathrm{PEI}$ composite, holes appear, and their size is somewhat irregular, spanning 5 to $20 \mathrm{~nm}$, which might be dependent on the embedding depth of the silica. Most of holes are round, however, indicating a single silica particle. This implies that silica is well dispersed in the PEI matrix. 20 wt\% SN2-PEI composite also exhibits good dispersion even though ellipsoidal shaped holes occasionally appear, which may result from aggregate 2-3 particles. Consequently, it is found that aggregation of between silica particles in PEI is minimized by dual silane surface modification.

The thermal property of the cured sample was investigated by DSC. Figure 7 shows DSC thermograms where the SN2 content varied from 0 to $20 \mathrm{wt} \%$, where the glass transition temperature $\left(T_{\mathrm{g}}\right)$ is indicated by vertical bars. $T_{\mathrm{g}}$ of each sample is displayed in terms of SN2 content in inset. $T_{\mathrm{g}}$ of neat PEI steeply increases from 90 to $107^{\circ} \mathrm{C}$ by adding up to $5 \mathrm{wt} \% \mathrm{SN} 2$. Above $5 \mathrm{wt} \% T_{\mathrm{g}}$ increment is retarded and reaches $113^{\circ} \mathrm{C}$ for $20 \mathrm{wt} \%$. The increase in $T_{\mathrm{g}}$ is attributed to 


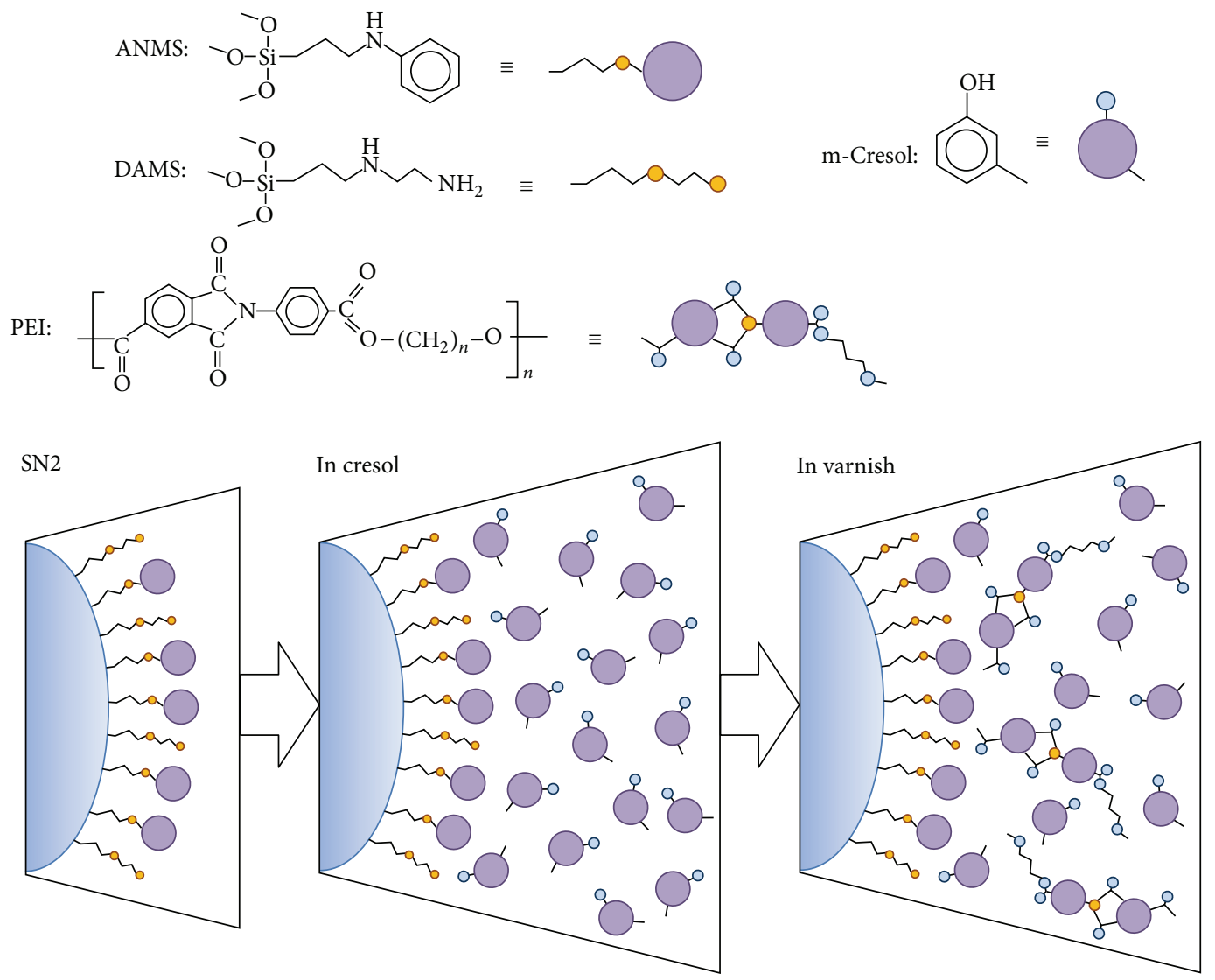

FIgURE 5: Schematic drawing for chemical similarity of silica surface with binary chemical compositions to cresol and PEI varnish.
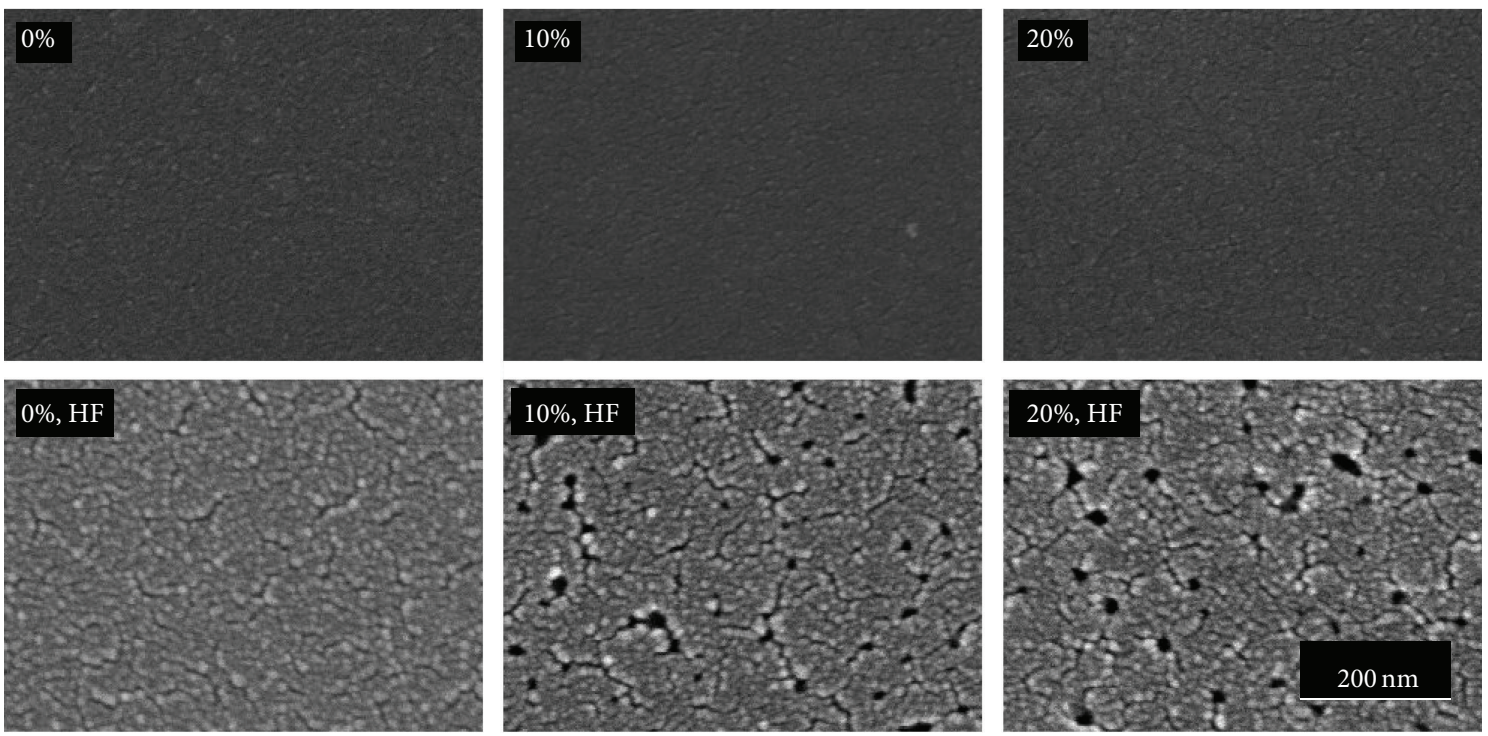

FIGURE 6: SEM images of thermally cured SN2-PEI nanocomposite before and after HF treatments.

a strong interaction between SN2 and the polymer matrix, which causes restricted motion of the polymer chains on the surface of the silica nanoparticles. A similar result was previously reported in which $T_{\mathrm{g}}$ of polyetherimide increased with an increase in inorganic nanofiller concentration as a result of good dispersion [23].
3.6. Fabrication of SN2-PEI Nanocomposite Enameled Wire and Surge Endurance Test. Fabrication of the SN2-PEI nanocomposite enameled wire has been done in a commercial coating facility. Both SN2 synthesis and dispersion in PEI varnish were done using a horn-type sonicator installed 3liter reaction chamber with a water circulating jacket. Singly 


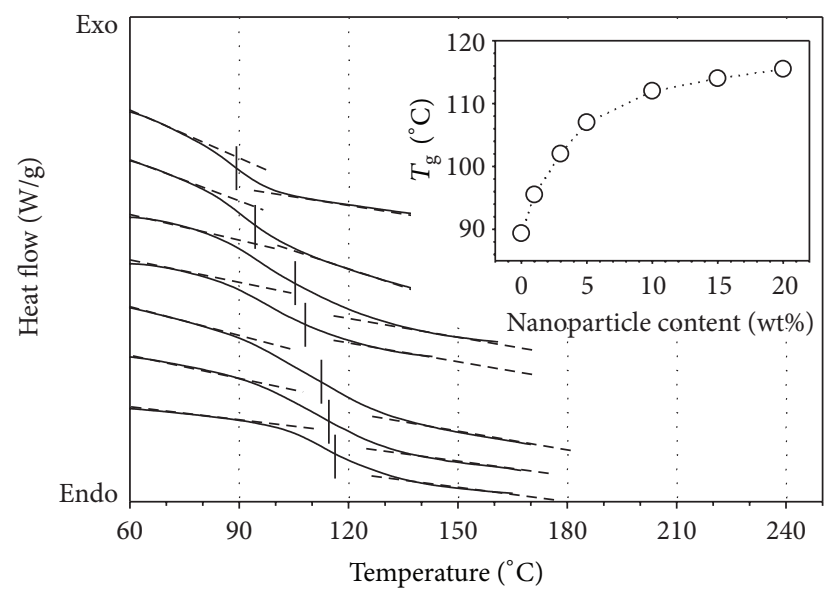

FIGURE 7: Thermograms of PEI nanocomposite measured by DSC with $0,1,3,5,10,15$, and 20 wt $\%$ SN2 from the top. Inset shows glass transition temperature $\left(T_{\mathrm{g}}\right)$ in terms of SN2 content obtained from the thermograms. Thermograms are moved down for clarity.

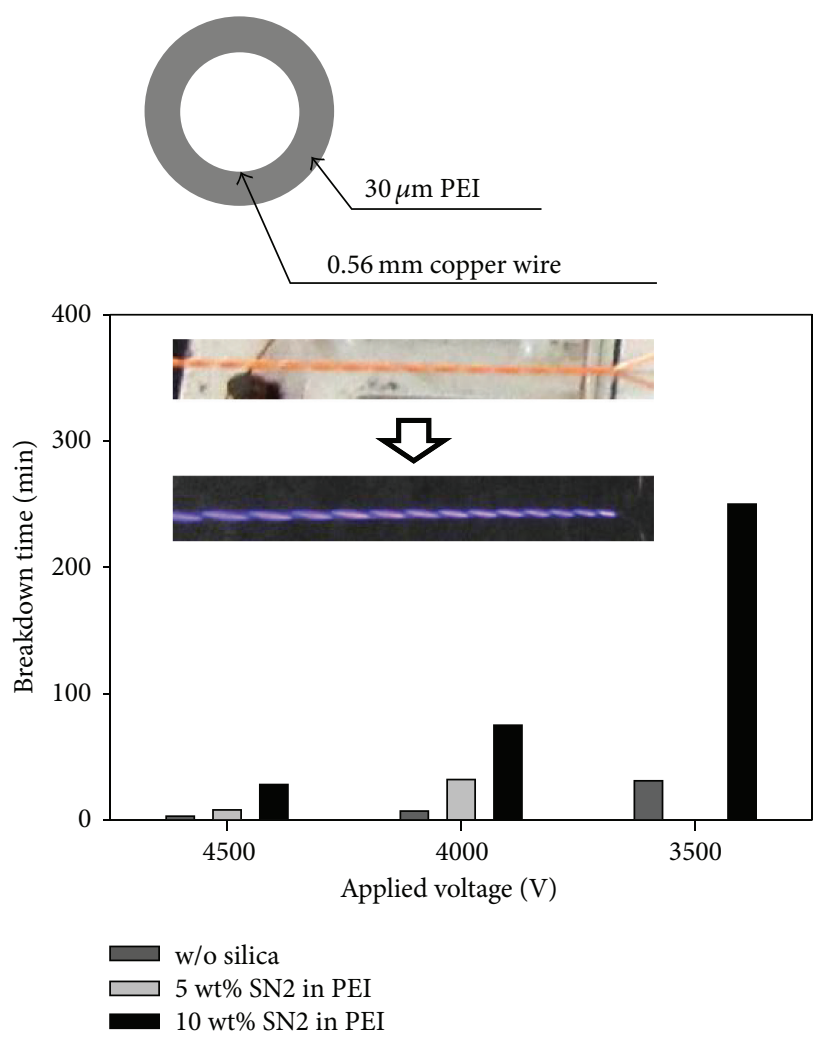

(a)
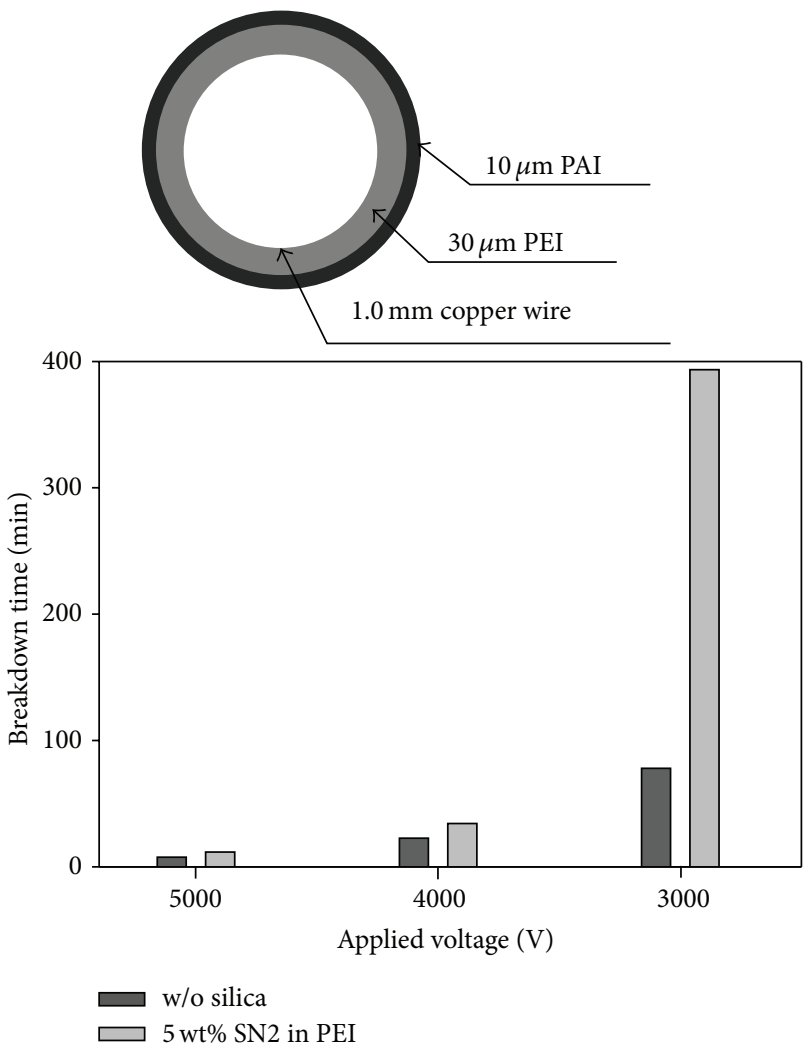

(b)

FIGURE 8: Applied voltage versus breakdown time of (a) PEI nanocomposite enameled wire and (b) PAI covered PEI nanocomposite enameled wire at $10 \mathrm{kHz}$. In inset, structure of both enameled wires and twisted wires for the test before and after voltage applied is displayed.

and doubly coated enameled wires were fabricated, which are PEI enameled wire and polyamideimide (PAI) covered PEI enameled wire as shown in Figure 8. PEI enameled wires including 0,5 , and $10 \mathrm{wt} \% \mathrm{SN} 2$ coated on copper wire with diameter of $0.56 \pm 0.01 \mathrm{~mm}$ were prepared. Coating thickness for each wire which was $29.5 \pm 0.5 \mu \mathrm{m}$ for PEI without SN2,
$30.0 \pm 0.5 \mu \mathrm{m}$ for $5 \mathrm{wt} \%$, and $30.8 \pm 0.5 \mu \mathrm{m}$ for $10 \mathrm{wt} \% \mathrm{SN} 2$ in PEI was obtained after repetitive coating 8 times, where the thickness slightly increases as the silica content increases because of increased viscosity of the varnish solution. PAI covered PEI enameled wire consists of an inner PEI layer and an outer self-lubricating PAI layer, which is a popular form 
of heat resistant enameled wire. The $30 \mu \mathrm{m}$ PEI layer from 8 coats of PEI varnish followed by $10 \mu \mathrm{m}$ PAI layer from 3 coats of PAI varnish was formed on the $1.0 \mathrm{~mm}$ copper wire in diameter, where the $5 \mathrm{wt} \% \mathrm{SN} 2$ was dispersed only in the PEI varnish.

A surge endurance test was done using twisted wires as shown in Figure 8. Voltage with square wave ranged from 3,000 to $4,500 \mathrm{~V}$ with $10 \mathrm{kHz}$ applied at room temperature, in which conditions PD was generated on the surface of the twisted wire. The breakdown time was measured when the insulation breaks down. In Figure 8(a), PEI enameled wire was broken down after $4 \mathrm{~min}$ at $4.5 \mathrm{kV}$. But by adding $5 \mathrm{wt} \%$ $\mathrm{SN} 2$, it endured longer times of $8 \mathrm{~min}$ and further addition of SN2 to $10 \mathrm{wt} \%$ leads the breakdown time to increase to $28 \mathrm{~min}$. This indicates that the embedded silica particles are well dispersed and effectively protect PEI layer from corrosion induced by PD. As the applied voltage decreases to 4.0 and $3.5 \mathrm{kV}$, the breakdown time difference between neat PEI and nanocomposite wire increases. It also increases exponentially with the increase in SN2 content. Similar results have been obtained for PAI covered PEI enameled wire as shown in Figure 8(b).

\section{Conclusions}

In this study, surge-resistant silica nanoparticle-PEI nanocomposite enameled wires were fabricated. For uniform dispersion of the silica nanoparticle in PEI varnish, its surface character was tailored by chemical modifications using two kinds of silanes so that the surface chemical composition would become similar to the varnish. The modification reaction was accelerated by ultrasound using a horn-type sonicator. After the modification, the nanoparticle with content of $20 \mathrm{wt} \%$ was well dispersed in both cresol and PEI varnish. Glass transition temperature of the silica-PEI nanocomposite was improved from 90 to $113^{\circ} \mathrm{C}$ by increasing the silica content up to $20 \mathrm{wt} \%$. The nanoparticle dispersed varnish was then applied for fabrication of the nanocomposite coated enameled wires in commercial facilities. The silicaPEI nanocomposite enameled wire exhibited enhanced surge resistance wherein the breakdown time increased by 7-8 times compared to that of neat PEI enameled wire. This surface modification method can be extended to nanoparticles for enhancing compatibility to various matrix environments.

\section{Conflict of Interests}

The authors declare that there is no conflict of interests regarding the publication of this paper.

\section{Acknowledgments}

This work was partly supported by Energy Technology Development (20131020000130, Development of Electrical Insulation Nanohybrid Materials for Motor (Rectangular) Coil) funded by the Ministry of Trade, Industry, and Energy, Korea, and Grant 15011002 from the Korea Research Institute of Standards and Science under the Project "Establishment of National Physical Measurements Standards and Improvements of Calibration/Measurement Capability."

\section{References}

[1] H. Kikuchi and H. Hanawa, "Inverter surge resistant enameled wire with nanocomposite insulating material," IEEE Transactions on Dielectrics and Electrical Insulation, vol. 19, no. 1, pp. 99-106, 2012.

[2] A. T. Hoang, Y. V. Serdyuk, and S. M. Gubanski, "Electrical characterization of a new enamel insulation," IEEE Transactions on Dielectrics and Electrical Insulation, vol. 21, no. 3, pp. 12911301, 2014.

[3] Y. Luo, G. Wu, J. Liu et al., "PD characteristics and microscopic analysis of polyimide film used as turn insulation in inverterfed motor," IEEE Transactions on Dielectrics and Electrical Insulation, vol. 21, no. 5, pp. 2237-2244, 2014.

[4] N. Hayakawa, F. Shimizu, and H. Okubo, "Estimation of partial discharge inception voltage of magnet wires under inverter surge voltage by volume-time theory," IEEE Transactions on Dielectrics and Electrical Insulation, vol. 19, no. 2, pp. 550-557, 2012.

[5] H. Kikuchi, H. Hanawa, and Y. Honda, "Development of polyamide-imide/silica nanocomposite enameled wire," Electronics and Communications in Japan, vol. 96, no. 6, pp. 41-48, 2013.

[6] T. Ozaki, T. Imai, F. Sawa, T. Shimizu, and F. Kanemitsu, "Partial discharge resistant enameled wire," in Proceedings of the International Symposium on Electrical Insulating Materials, vol. 1, pp. 184-187, IEEE, Kitakyushu, Japan, June 2005.

[7] T. Tanaka, G. C. Montanari, and R. Mülhaupt, "Polymer nanocomposites as dielectrics and electrical insulation- perspectives for processing technologies, material characterization and future applications," IEEE Transactions on Dielectrics and Electrical Insulation, vol. 11, no. 5, pp. 763-784, 2004.

[8] J. C. Fothergill, J. K. Nelson, and M. Fu, "Dielectric properties of epoxy nanocomposites containing $\mathrm{TiO}_{2}, \mathrm{Al}_{2} \mathrm{O}_{3}$ and $\mathrm{ZnO}$ fillers," in Proceedings of the IEEE Electrical Insulation and Dielectric Phenomena, Annual Report Conference (CEIDP '04), pp. 406-409, usa, October 2004.

[9] M. Kozako, R. Kido, N. Fuse, Y. Ohki, T. Okamoto, and T. Tanaka, "Difference in surface degradation due to partial discharges between polyamide nanocomposite and microcomposite [electrical insulation applications]," in Proceedings of the Annual Report Conference on Electrical Insulation and Dielectric Phenomena (CEIDP '04), pp. 398-401, IEEE, Vancouver, Canada, October 2004.

[10] J. K. Nelson, J. C. Fothergill, L. A. Dissado, and W. Peasgood, "Towards an understanding of nanometric dielectrics," in Proceedings of the Annual Report Conference on Electrical Insulation and Dielectric Phenomena (CEIDP '02), pp. 295-298, IEEE, October 2002.

[11] Y. Nakamura, H. Inano, S. Hiroshima, T. Hirose, M. Hamaguchi, and H. Okubo, "Partial discharge resistant aging mechanism of nanocomposite enamel wires under repetitive surge voltage condition," in Proceedings of the Annual Report Conference on Electrical Insulation and Dielectric Phenomena (CEIDP '08), pp. 375-378, Quebec, Canada, October 2008.

[12] M. Son, Y. Ha, M.-C. Choi et al., "Microstructure and properties of polyamideimide/silica hybrids compatibilized with 3aminopropyltriethoxysilane," European Polymer Journal, vol. 44, no. 7, pp. 2236-2243, 2008. 
[13] X. Ma, N.-H. Lee, H.-J. Oh, J.-S. Hwang, and S.-J. Kim, "Preparation and characterization of silica/polyamide-imide nanocomposite thin films," Nanoscale Research Letters, vol. 5, no. 11, pp. 1846-1851, 2010.

[14] F. M. John, E. S. Howard, and J. Z. Edmund, "Polyester-polyimide wire enamel," Google Patents, 1969.

[15] H. Kikuchi, Y. Yukimori, and S. Itonaga, "Inverter-surgeresistant enameled wire based on nano-composite insulating material," Hitachi Cable Review, vol. 21, pp. 55-62, 2002.

[16] B. Gornicka and E. Prociow, "Polyester and polyesterimide compounds with nanofillers for impregnating of electrical motors," Acta Physica Polonica A, vol. 115, no. 4, pp. 842-845, 2009.

[17] Y. Uozumi, Y. Kikuchi, N. Fukumoto, M. Nagata, Y. Wakimoto, and T. Yoshimitsu, "Characteristics of partial discharge and time to breakdown of nanocomposite enameled wire," in Proceedings of the Annual Report-Conference on Electrical Insulation and Dielectric Phenomena (CEIDP '07), pp. 228-231, Vancouver, Canada, 2007.

[18] K. Inuzuka, H. Inano, N. Hayakawa, T. Hirose, M. Hamaguchi, and H. Okubo, "Partial discharge characteristics of nanocomposite enameled wire for inverter-fed motor," in Proceedings of the Conference on Electrical Insulation and Dielectric Phenomena (CEIDP '06), pp. 594-597, IEEE, Kansas, Mo, USA, October 2006.

[19] M. Mesaki and H. Goda, "Hybrid composites of polyamideimide and silica applied to wire insulation," in Proceedings of the Electrical Insulation Conference and Electrical Manufacturing \& Coil Winding Conference, pp. 1-4, IEEE, Cincinnati, Ohio, USA, October 2001.

[20] S. Al-Kandary, A. A. M. Ali, and Z. Ahmad, "New polyimidesilica nano-composites from the sol-gel process using organically-modified silica network structure," Journal of Materials Science, vol. 41, no. 10, pp. 2907-2914, 2006.

[21] H. T. Wang, W. Zhong, P. Xu, and Q. Du, "Properties of polyimide/silica nanohybrids from silicic acid oligomer," Macromolecular Materials and Engineering, vol. 289, no. 9, pp. 793799, 2004.

[22] Y. Kim, S.-Y. Park, S. Y. Kwon, S.-J. Kim, J. Kim, and Y.-S. Seo, "Enhanced thermal resistance of nanocomposite enameled wire prepared from surface modified silica nanoparticle," Thermochimica Acta, vol. 542, pp. 62-68, 2012.

[23] B.-K. Chen, C.-T. Su, M.-C. Tseng, and S.-Y. Tsay, "Preparation of polyetherimide nanocomposites with improved thermal, mechanical and dielectric properties," Polymer Bulletin, vol. 57, no. 5, pp. 671-681, 2006. 

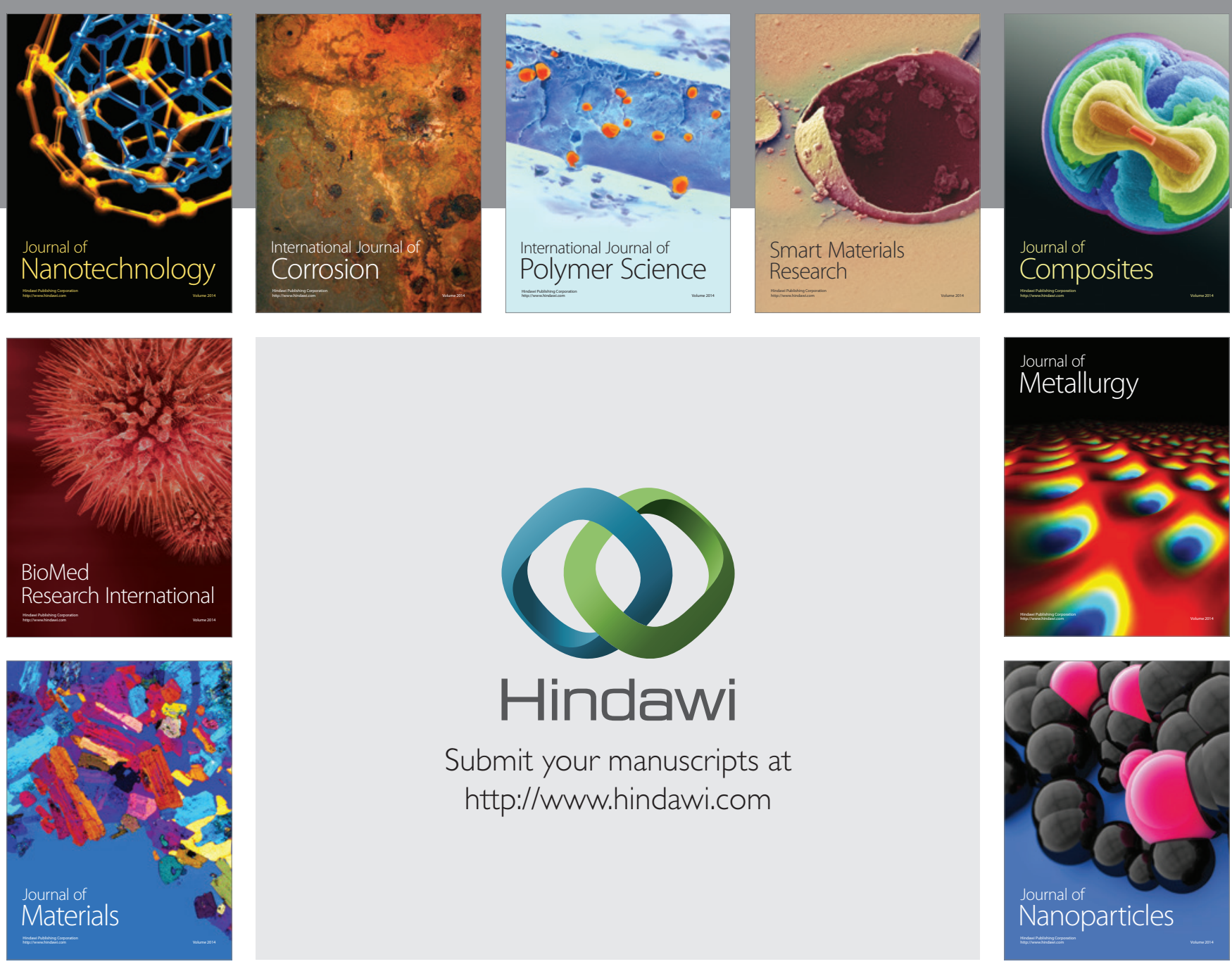

Submit your manuscripts at http://www.hindawi.com
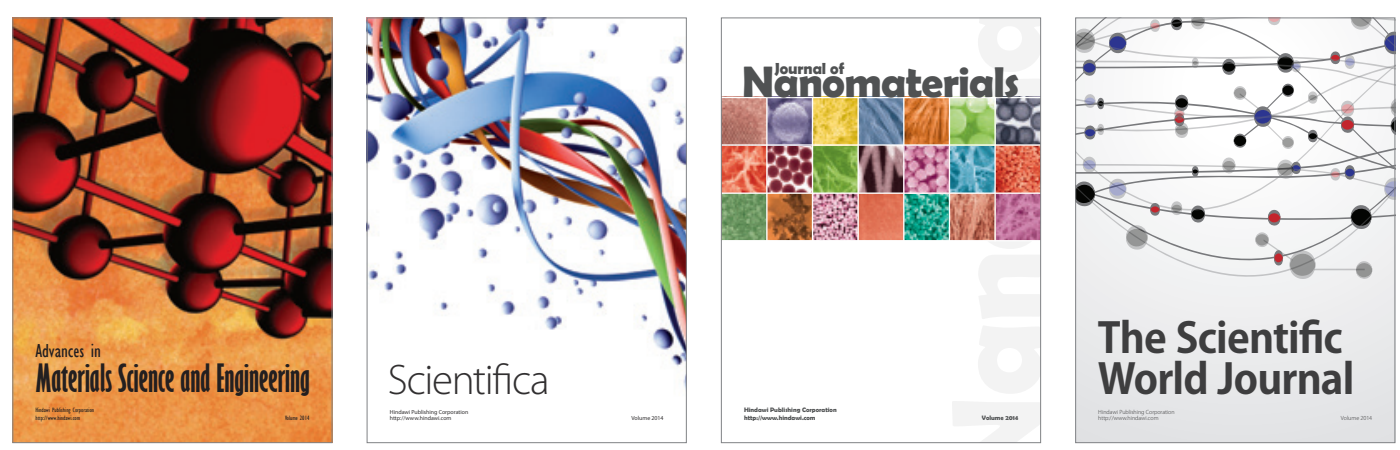

\section{The Scientific World Journal}
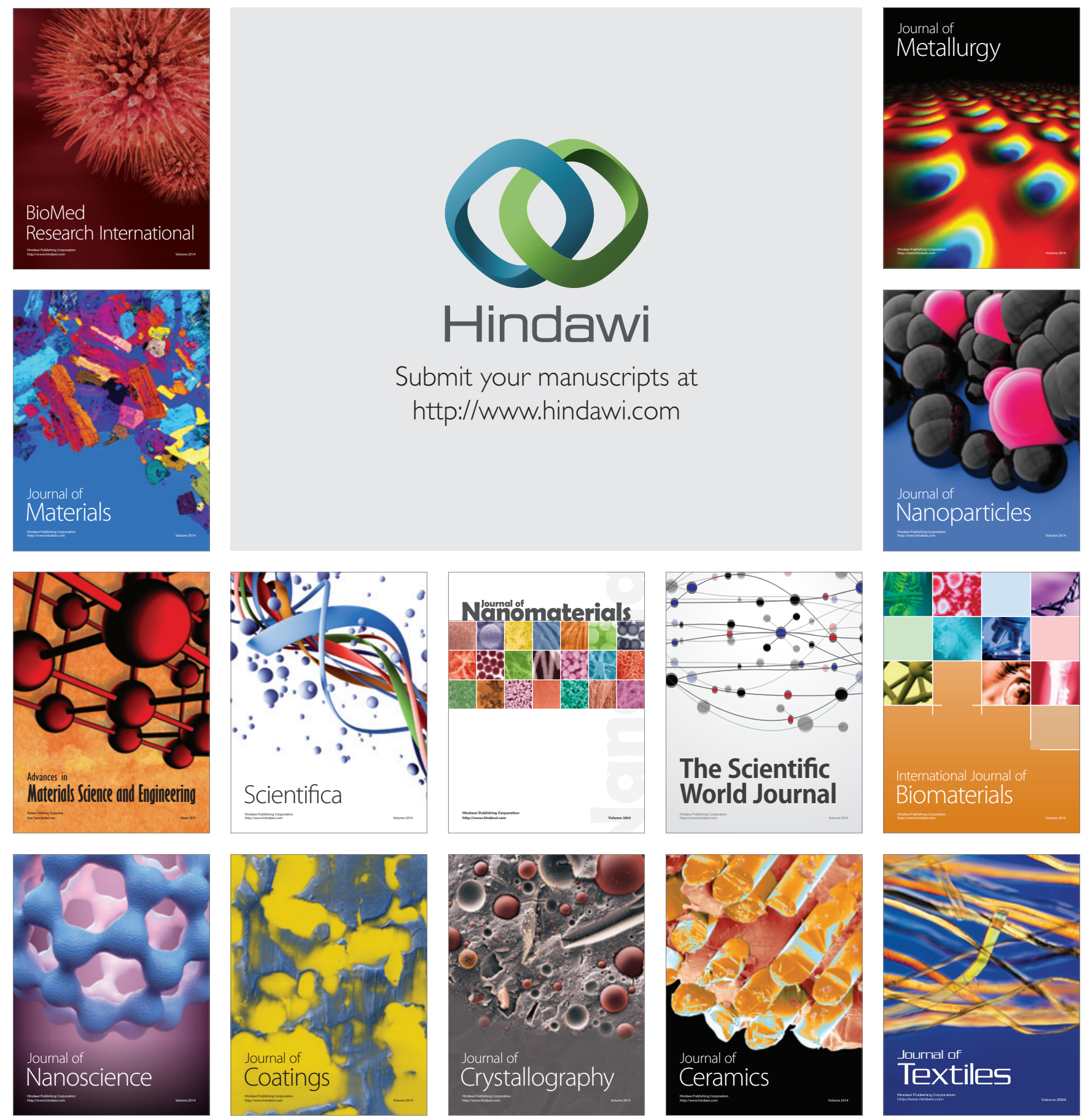